\title{
Linguagem e hermenêutica bíblica na filosofia de Benedictus de Spinoza
}

\section{Language and biblical hermeneutics in Benedictus de Spinoza's philosophy}

\section{CARLOS WAGNER BENEVIDES GOMES ${ }^{1}$}

Resumo: Este artigo tem como objetivo expor o problema da crítica à linguagem e da interpretação em Benedictus de Spinoza (1632-1677), filósofo holandês, nas suas demais obras voltadas à ética, à ontologia e à teoria do conhecimento como a Ética, Tratado da Correção do Intelecto, Breve Tratado e outros escritos. Pretendemos mostrar que, mesmo que não sistematizados pelo autor, existem alguns problemas linguísticos e interpretativos fundamentais para a elaboração de seu método racionalista. Portanto, explicitaremos sua hermenêutica bíblica a partir do método histórico-crítico, na obra Tratado Teológico-Político, e de uma gramática da língua hebraica que consagrou Spinoza como um dos primeiros exegetas da modernidade.

Palavras-Chave: Spinoza. Linguagem. Hermenêutica.

Abstract: This article aims to expose the problem of critique of language and interpretation in Benedictus de Spinoza (1632-1677), Dutch philosopher, in his other works focused on ethics, ontology and the theory of knowledge as the Ethics, Treatise on the Emendation of the Intellect, Short Treatise and other writings. We intend to show that even if not systematized by the author, there are some fundamental linguistic and interpretive problems for the development of its rationalistic method. Therefore, we present the problem of biblical hermeneutics from the historical-critical method, in the work Theological-Political Treatise, and a

\footnotetext{
${ }^{1}$ Bolsista da CAPES. Graduado em Filosofia pela Universidade Estadual do Ceará UECE. Mestrando em Filosofia pela Universidade Federal do Ceará - UFC. Membro do Grupo de Trabalho Benedictus de Spinoza - UECE. E-mail: wagnercarlos92@gmail.com.
} 
grammar of the Hebrew language that consecrated Spinoza as one of the first exegetes of modernity.

Keywords: Spinoza. Language. Hermeneutics.

\section{Introdução}

No entanto, é possível falar num problema da linguagem na filosofia de Espinosa [...] Entre várias ocasiões, Espinosa trata explicitamente da linguagem: no capítulo XVI da Parte II do Breve Tratado, no Tratado da Reforma da Inteligência, nos livros II e IV da Ética e no capítulo VII do Tratado Teológico-Político (CHAUI, 1981, p. 11).

Este artigo tem como objetivo inferir uma dupla problemática: a linguagem e a hermenêutica na filosofia de Benedictus de Spinoza. Primeiramente, uma das principais questões suscitadas foram a imaginação, o pensamento e a linguagem que dizem respeito tanto a ontologia como a teoria do conhecimento do filósofo holandês. Tomamos como referenciais teóricos algumas obras de Spinoza como a Ética, complementar a outras obras como o Tratado da Correção do Intelecto, Princípios de Filosofia Cartesiana e Breve Tratado. Além disso, dentro da proposta de agenciar uma análise linguística em Spinoza no que se refere à questão teológico-política, explicitamos no Tratado Teológico-Político e no Compêndio de Gramática da Língua Hebraica, a hermenêutica das Sagradas Escrituras que parte de uma interpretação filológica e histórico-crítica.

Por conseguinte, utilizamos a leitura complementar de comentadores como Marilena Chauí com Espinosa: Uma Filosofia da Liberdade (1995) e Da Realidade sem Mistérios ao Mistério do Mundo 
(1981) numa análise histórico-filosófica dos principais pontos teóricos de Spinoza inferidos à questão da linguagem. Sobre a questão da gramática hebraica e a interpretação bíblica, Homero Santiago com Geometria do Instituído: Estudo sobre a gramática hebraica (2014). Também utilizamos os seguintes artigos pertinentes a esta pesquisa: Introdução ao problema da linguagem na filosofia de Spinoza (2010), de Gabriel Dirma de Araújo Leitão e Espinoza e a Linguagem (2011), de Olga Pombo entre outros textos que colaboraram para esta pesquisa.

Para uma exposição sistemática e objetiva, dividimos este artigo em cinco tópicos. No primeiro [O sistema ontológico da Ética], explicitamos de forma geral os principais elementos conceituais e estruturais metodológicos da obra principal de Spinoza, a Ética, além de demonstrar a teoria ontológica da substância, dos atributos e dos modos. No segundo [A Ideia Verdadeira], expomos o viés epistemológico que parte da ontologia spinozana, tratando assim, de questões como a Ideia adequada ou verdadeira, a Ideia inadequada ou falsa presentes tanto na Ética como no Tratado da Correção do Intelecto. Dando continuidade à teoria do conhecimento de Spinoza, o terceiro tópico [Dos gêneros de conhecimento e a questão do método], aborda a questão da imaginação, do pensamento racional e intuitivo onde se explicita o problema da linguagem como um modo de imaginar e como um conhecimento de primeiro gênero em conflito com outros gêneros relacionados ao modo de pensar. Além disso, o problema do método filosófico empregado por Spinoza a partir do conceito de ideia verdadeira.

O quarto tópico [A Crítica spinozana acerca da linguagem] explora um dos problemas principais deste artigo, ou seja, a tentativa 
de inserir Spinoza como um filósofo que discute, mesmo que não de forma sistemática, a questão da linguagem numa perspectiva crítica a partir de exemplos específicos dados na Ética, no Breve Tratado e no Tratado da Correção do Intelecto. Por fim, no último tópico [A hermenêutica bíblica de Spinoza e o método histórico-crítico], apresentamos a teoria da interpretação de Spinoza das Sagradas Escrituras a partir do chamado método histórico-crítico presente nas obras Tratado Teológico-Político e Compêndio de gramática da língua hebraica.

\section{O Sistema ontológico da Ética}

A Ética, seguida do subtítulo demonstrada segundo a ordem geométrica (Ethica ordine geometrico demonstrata), é a obra principal de Spinoza que foi publicada postumamente em 1677. Foi escrita em latim e em ordem geométrica (ordine geometrico) segundo os Elementos de Geometria de Euclides. Spinoza a escreve de forma euclidiana, com definições, axiomas, proposições, demonstrações, escólios, corolários, etc ${ }^{2}$. A Ética foi dividida em cinco partes ${ }^{3}$ dos quais tratam os seguintes temas: Deus, o Corpo e a Mente, os Afetos, a Servidão e a Liberdade Humana. A filosofia característica da obra é evidente por si mesma. Organizada e

${ }^{2} \mathrm{O}$ método geométrico (more geométrico) utiliza as definições e os axiomas que são, por exemplo, notum per si, ou seja, conceitos ou verdades universais que não precisam ser demonstrados empiricamente. As proposições são os enunciados que exprimem suas explicações, como as demonstrações, e seus aprofundamentos e consequências são os escólios e os corolários.

3 Tratam-se respectivamente da Parte I (De Deus), Parte II (Da Natureza e origem da Mente), Parte III (Da origem e natureza dos Afetos), Parte IV (Da Servidão humana, ou a Força dos Afetos) e Parte V (Da Potência do intelecto ou da Liberdade Humana). 
estruturada com todo um raciocínio lógico, a Ética mostra-se preocupada com a demonstração clara e distinta de cada proposição enunciada. É interessante notar que no texto da Ética, há sempre a retomada de referências de outras proposições ou outros conceitos já mencionados antes pelo autor, evitando, assim, o máximo a contradição.

O método científico empregado na Ética, por assim dizer, é o da dedução, uma vez que Spinoza parte de conceitos universais como Deus (Parte I) e conclui com uma questão de filosofia prática, ou seja, da Liberdade Humana (Parte V). Segundo a Definição 6 da Parte I da Ética: "Por Deus compreendo um ente absolutamente infinito, isto é, uma substância que consiste de infinitos atributos, cada um dos quais exprime uma essência eterna e infinita" (SPINOZA, 2010, p.13). Trata-se de uma ética que, diferente de uma regra moral (como a normatividade de um dever-ser) imposta e prescrita à vida, reflete as potências de agir e de pensar do homem, mostrando a este os caminhos à beatitude e à liberdade. Ou seja: é uma filosofia prática voltada para a reflexão do agir e de suas potencialidades, pois, a questão que Spinoza coloca é o que podemos e até onde podemos, diferentemente, da questão do que devemos fazer. A ética spinozana, por conseguinte, tem como principais objetivos mostrar a necessidade do conhecimento da causa (Deus), das ações como causas adequadas e os bons encontros ${ }^{4}$ (que

\footnotetext{
${ }^{4}$ Na Parte III (Da Origem e Natureza dos Afetos) da Ética, Spinoza expôs sua teoria das paixões ao tratar dos afetos que ora podem estimular, refrear ou serem indiferentes para nossa potência (potentia). Assim, temos bons encontros (occursus) se somos afetados por afetos alegres (o amor, a alegria), por outro lado, temos maus encontros se somos afetados por afetos tristes (o ódio, a tristeza, o medo).
} 
aumentam a potência de agir), por exemplo, garantindo ao homem o fim de sua servidão e de sua superstição, ou seja, sua liberdade.

A Ética tem como principal "tríade" ontológica, a substância, os atributos e os modos. A substância seria Deus enquanto é causa de si e imanente ao todo. Os atributos são aquilo de essencial que o intelecto percebe da Substância, e os modos, por sua vez, são as expressões finitas ou modificações da Substância. Spinoza apresenta os conceitos de substância, de atributo e de modo nas definições 3, 4 e 5 da Parte I da Ética. Na definição 3 temos o seguinte: "Por substância compreendo aquilo que existe em si mesmo e que por si mesmo é concebido, isto é, aquilo cujo conceito não exige o conceito de outra coisa da qual deva ser formado" (SPINOZA, 2010, p. 13). Na definição 4, os atributos aparecem como expressões substanciais infinitas e aquilo que o intelecto percebe como essência da substância.

Por fim, na definição 5, temos os modos enquanto as afecções substanciais e aquilo que existe em outra coisa. Os homens, por exemplo, são dois modos finitos (o corpo e a mente ou alma, segundo alguns tradutores 5 ) da substância e que fazem parte de dois atributos substanciais, quais sejam, o pensamento e a extensão. Este problema ontológico desemboca numa questão epistemológica como a relação entre a mente e o corpo enquanto a ideia e seu objeto, pois, o "objeto da ideia que constitui a mente humana é o corpo, ou

5 "O francês, de fato, não dispõe de um termo equivalente ao latim mens, pois nenhum substantivo corresponde, em francês, ao adjetivo 'mental' (a diferença do italiano, por exemplo, que dispõe do substantivo mente, e porque traduzir mens por 'le mental [o mental]' seria tão cômico quanto anacrônico" (RAMOND, 2010, p. 22). Spinoza, por sua vez, empregou o termo latino mens para mente dissociandose da noção clássica de alma (anima) da teologia-metafísica. 
seja, um modo definido da extensão, existente em ato e nenhuma outra coisa" (SPINOZA, 2010, p. 97). Trata-se da chamada doutrina do paralelismo ou a união psicofísica, na proposição 13 da Parte II ( $A$ natureza e origem da mente) da Ética, segundo a qual não há superioridade entre o corpo e a mente, mas uma simultaneidade em suas ações e paixões.

Nesta mesma parte da Ética, Spinoza trata de um conceito como o de Ideia que será fundamental para explicar e tentar inferir um problema filosófico da linguagem tal como saber em que consistem as imagens e as palavras ante as ideias. Além disso, Spinoza trata na Ética, a epistemologia da Ideia adequada (idea adaequata), da Ideia inadequada (idea inadaequata) e dos gêneros de conhecimento (generis cognitione) onde questionaremos em que nível ou grau de conhecimento se enquadraria a linguagem como um modo de imaginar. Segundo Marilena Chauí (1981, p. 21), "no estudo da linguagem veremos as diferentes modalidades de relação entre imaginação e intelecto que aparecem segundo a natureza do problema discutido." E é através deste problema envolvendo a relação entre a imaginação e o intelecto que nortearemos o problema da linguagem na filosofia de Spinoza.

\section{A ideia verdadeira}

No início da Parte II da Ética, em Definições, Spinoza tratou acerca do problema da ideia (idea). Assim, diz na Definição 3:

[...] Por ideia compreendo um conceito da Mente, que a mente forma porque é uma coisa pensante. Explicação. Digo conceito e não percepção, porque a palavra percepção parece indicar que a mente é passiva relativamente ao objeto, enquanto conceito parece exprimir uma ação da mente (SPINOZA, 2010, p. 79). 
Logo após, o filósofo holandês explica outro conceito que será importante para entender sua teoria do conhecimento e seu método filosófico na busca do verdadeiro, a ideia adequada: "Por ideia adequada compreendo uma ideia que, enquanto considerada em si mesma, sem relação com o objeto, tem todas as propriedades ou denominações intrínsecas de uma ideia verdadeira" (ibidem). Segundo Spinoza, todas as ideias estão referidas a Deus, pois são verdadeiras e estão em perfeita concordância com seus ideados. Segundo a demonstração da Proposição 43 da Parte II da Ética: "Em nós, uma ideia verdadeira é aquela que é adequada em Deus enquanto Deus é explicado pela natureza da mente”. (SPINOZA, 2010, p. 137). Além disso, como é apresentado no escólio desta mesma proposição, "[...] ter uma ideia verdadeira significa senão conhecer uma coisa perfeitamente, ou seja, muitíssimo bem" (ibidem). E, consequentemente, levando ao questionamento de Spinoza: “[...] o que pode existir de mais claro e certo do que uma ideia verdadeira e que possa servir como norma de verdade?" (ibidem). Porém, Teixeira (2001, p. 41) ressaltou um problema: “[...] afirmar que 'temos uma idéia verdadeira', visto que é a idéia verdadeira que procuramos e um paradoxo afirmar que a idéia verdadeira deve ser o ponto de partida do método". Por outro lado, segundo o filósofo holandês, existe em nós, por concebermos ideias confusas e mutiladas das coisas, uma ideia inadequada (o falso). A falsidade, neste sentido, consiste na privação de conhecimento ou na parcialidade deste que as ideias inadequadas mutiladas e confusas envolvem.

No Tratado da Correção do Intelecto (Tractatus de Intellectus 
Emendatione $)^{6}$ obra inacabada, temos também a questão do conceito de ideia seguida da concepção de ideia verdadeira (idea vera) segundo a qual "[...] é algo diverso do seu ideado, por que uma coisa é o círculo, outra é a idéia de círculo" (SPINOZA, 1983, p. 49). exemplo do círculo também foi utilizado na Parte II da Ética quando Spinoza explica sua proposição 7 segundo a qual a ordem e a conexão das ideias são a mesma coisa que a ordem e a conexão das coisas, pois, uma coisa é o círculo existente na natureza, outra é a ideia deste círculo existente na natureza. Segundo Spinoza, a essência objetiva de uma coisa é a ideia dessa coisa enquanto a sua essência formal é aquela que visa à coisa em sua realidade material ou sua forma. Por conseguinte, "[...] estabelecendo assim uma simetria perfeita entre uma coisa e sua essência: a essência sendo essência da coisa, e a coisa, essência da essência" (RAMOND, 2010, p. 36). A ideia verdadeira, por sua vez, deve existir antes de tudo em nós, como instrumento inato; logo, ela se apresenta objetivamente do mesmo modo que se apresenta realmente seu ideado. É uma ideia que basta a si mesma, pois, não tem necessidade da confirmação pela concordância com um objeto exterior. Assim, a mente deve se dirigir segundo a norma de uma existente ideia verdadeira. Mas, segundo Teixeira (2001), não basta que as ideias sejam claras e distintas; é necessário que façam parte da infinita cadeia de Deus (o que exigirá outro tipo de conhecimento).

${ }^{6}$ Existem outras traduções que se intitulam Tratado da Emenda do Intelecto ou Tratado da Reforma da Inteligência. Utilizamos a tradução portuguesa SPINOZA, B. Tratado da Correção do Intelecto. In: Espinosa. Tradução e notas: Carlos Lopez de Mattos. São Paulo: Abril, 1983. (Col. Os Pensadores). 


\section{Dos gêneros de conhecimento e a questão do método}

Outra questão importante na Ética que sucede a ideia adequada (idea adaequata) é a problemática do conhecimento. Para Spinoza, definir o conhecimento é defini-lo pelos seus gêneros ou os modos de percepção (modi percipiendi), conceitos presentes também no Tratado da Correção do Intelecto (1661) e no Breve Tratado (1650166o)7. Spinoza descreve, na Proposição 40 da Parte II da Ética, o processo como se dá os gêneros de conhecimento a partir do momento em que nós percebemos muitas coisas e formamos noções universais:

1. A partir de coisas singulares que os sentidos representam mutilada, confusamente, e sem a ordem própria do intelecto. Por isso, passei a chamar essas percepções de conhecimento originado da experiência errática. 2. A partir de signos, por exemplo, por ter ouvido ou lido certas palavras, nós nos recordamos das coisas e delas formamos idéias semelhantes àquelas por meio das quais imaginamos as coisas. [Conhecimento de primeiro gênero: opinião ou imaginação]. 3. Por termos, finalmente, noções comuns e idéias adequadas das propriedades das coisas [Conhecimento de segundo gênero: Razão] (SPINOZA, 2010, p. 133-135).

Por fim, temos, segundo Spinoza, um conhecimento de terceiro

7 O Breve Tratado foi considerado um dos primeiros escritos de Spinoza. Segundo os comentadores de Spinoza, há uma tradução latina, mas existem dois manuscritos holandeses desta obra cujas anotações parecem de ouvintes onde Spinoza teria contribuído em algumas partes. Sobre a questão dos modos de percepção, diz Spinoza (2012, p. 92), precisamente, na Parte II, capítulo I ( $D a$ opinião, da crença e do saber): "O primeiro modo [crença] está geralmente sujeito ao erro; o segundo e o terceiro [verdadeira crença e intelecção clara e distinta], embora difiram um do outro, não podem propriamente levar ao erro.” 
gênero: a intuição (scientia intuitiva) que é "[...] parte da ideia adequada da essência formal de certos atributos de Deus para chegar ao conhecimento adequado da essência das coisas" (SPINOZA, 2010, p. 135). Por conseguinte, podemos definir os principais aspectos dos gêneros de conhecimento da seguinte forma: 1) Através da imaginação (imaginatio) como um conjunto de ideias inadequadas (passivas); imagens confusas e obscuras da nossa experiência sensível. 2) Pela razão (ratio) enquanto noções comuns sobre leis necessárias entre um todo e suas partes; é também a consciência das relações de causas e efeitos. E, por fim, 3) a intuição (intuitione) que é a ideia adequada (ativa) das coisas que conhecendo sua natureza íntima pelas suas causas e efeitos necessários, ou seja, é a certeza intelectual que nos faz saber que sabemos. Spinoza (2010, p. 131-135) conclui, nas Proposições 40 e 42, que o conhecimento de primeiro gênero (imaginativo) é a única causa de falsidade enquanto o de segundo e o de terceiro (racional e intuitivo) são verdadeiros. E, por conseguinte, o conhecimento de segundo e de terceiro gênero nos ensinam a distinguir o verdadeiro do falso.

No Tratado da Correção do Intelecto, Spinoza elabora um método no qual propõe uma correção intelectiva, projeto este similar à dúvida metódica de Descartes quando se pretende duvidar de todas as opiniões tomadas como sólidas a partir dos sentidos. Spinoza discute a questão da correção do intelecto (intellectus emendatione) $)^{8}$ que seria capaz de oferecer ao homem recursos para chegar à liberdade e ao bem verdadeiro. "Antes de tudo, porém, deve

${ }^{8}$ Segundo Teixeira (2001, p.21-22), "Veremos que essa emendatio se resume em encontrar uma ordem superior segundo a qual se possa deduzir a verdade total do universo e que essa ordem superior consiste em partir da idéia do Ser Perfeito [...]."

Diaphonía, ISSN 2446-7413, v. 2, n. I, 2016 
excogitar-se o modo de curar o intelecto e purificá-lo quanto possível desde o começo, a fim de que entenda tudo felizmente sem erro e da melhor maneira" (SPINOZA, 1983, p. 45). Segundo Chauí (1995), esta correção se dá pelo caminho reflexivo onde há a reflexão do intelecto sobre si mesmo como capacidade inata de conhecimento verdadeiro. É a partir desta reflexão sobre o caminho reto no qual nos esforçamos para alcançar um conhecimento nos ditames da razão é que Spinoza propõe um método.

Para Spinoza, o conhecimento verdadeiro se dá na reflexão e consiste em conhecer as coisas por suas causas primeiras (próprios dos conhecimentos de segundo e do terceiro gêneros). Como objetivos deste método temos "[...] pela primeira parte [...], que é como dissemos, distinguir e separar das outras percepções a idéia verdadeira e coibir a mente para que não confunda com as verdadeiras e falsas, as fictícias e as duvidosas" (SPINOZA, 1983, p. 53). A verdade é revelada a si mesmo na qual todas as coisas lhe advêm, pois, a verdade é norma ou índice de si mesma (index sui). A certeza da verdade é, para Spinoza, dependente de uma ideia verdadeira, assim, não há necessidade que para que tenhamos que saber que sabemos. Não existirá um método como conhecimento reflexivo se antes não houver uma ideia da ideia que seja clara e distinta. Spinoza, precisamente, classifica os tipos de ideias das quais o intelecto é, negativamente, passivo devendo evitá-las. Temos então: 1) a ideia fictícia como aquela que é impossível, de natureza contraditória e que relaciona-se ao fingir. 2) a ideia falsa: se a existência da coisa não for uma verdade eterna como é sua essência e 
mostrar impossibilidades de existir. Por fim, 3) a ideia duvidosa9 como aquela gerada pela desordem das coisas investigadas, ou seja, a "[...] ideia que não é tão clara e distinta que possamos dela concluir algo de certo acerca do que se duvida" (SPINOZA,1983, p. 61).

Por sua vez, a imaginação é um conhecimento de primeiro gênero que, diferente da intelecção, é um efeito da ação de causas externas sobre nós e não nos oferece a própria coisa tal como é em si mesma. "A imaginação possui suas leis necessárias de operação e a linguagem, enquanto produto da imaginação, não é um amontoado de contingências, mas um conjunto de acontecimentos inteligíveis" (CHAUI, 1981, p. 35). Segue-se que, a imaginação consiste em apreender a natureza partindo de qualidades que atribuem o homem. Ela é, pois, falsa quando tomamos como parte do intelecto. Assim, também é a memória como sensação das impressões do cérebro junto com o pensamento de uma determinada duração:

Compreendemos, assim, claramente, o que é a memória. Não é, com efeito, senão uma certa concatenação de ideias, as quais envolvem a natureza das coisas exteriores ao corpo humano, e que se faz, na mente, segundo a ordem e a concatenação das afecções do corpo humano (SPINOZA, 2010, p. 113).

\section{A crítica spinozana acerca da linguagem}

Como foi dito acima, Spinoza não dedicou nenhum tratado filosófico voltado para uma questão sistemática sobre a linguagem, mas também não há uma ausência de problemas voltados para uma

9 Cf. GLEIZER, 2014, p. 107: "A Razão de duvidar é, assim, uma ideia confusa, imperfeita e inadequada, e não é uma ideia certa. Ou seja, o jogo da dúvida (e do ceticismo) não pressupõe a certeza, o que se encontra na sua raiz é a ignorância.”. 
crítica à linguagem ${ }^{10}$. Spinoza, a partir do Tratado Teológico-Politico (Tratactus Teologicus Politicus) consagrou-se como um dos primeiros exegetas modernos da Bíblia por meio da criação de um método histórico-crítico (como veremos adiante com mais detalhes) capaz de interpretar as Escrituras de forma filológica e históricofilosófica. No Tratado da Correção do Intelecto, no Breve Tratado ${ }^{11} \mathrm{e}$, sobretudo, na Ética ${ }^{12}$, existe uma preocupação epistemológica comum sobre os conceitos de imagens, de nomes e de palavras. Pelo menos na Parte II da Ética, o problema da linguagem começa a ser percebido através de alguns exemplos da experiência que o filósofo nos fornece:

Compreendemos, assim, claramente, por que a mente passa imediatamente de um pensamento de uma coisa para o pensamento de uma outra que não tem com a primeira

10"Decerto a crítica à linguagem não é um movimento original de Spinoza. A hesitação em relação à possibilidade de uma expressão linguística de determinados conhecimentos - e com especial ênfase em relação à possibilidade de que uma tal expressão se dê por escrito - é um dos mais onipresentes leitmotiv da história do pensamento" (LEITÃO, 2010, p. 30).

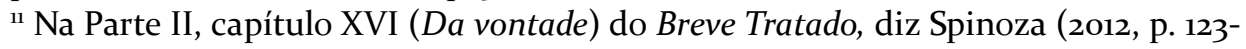
124), acerca das palavras: "é bem verdade (se existem razões que nos incitem a isso) que com palavras ou outros meios podemos dar a conhecer a outro algo sobre a coisa que seja diferente daquilo de que somos cônscios; porém, nem com palavras, nem com nenhum outro meio poderemos lograr sentir as coisas de maneira diferente de como as sentimos; isso é impossível, o que é claro a todos que, fora do uso das palavras ou de outros signos, dirigiram sua atenção alguma vez somente ao seu intelecto."

12 "Em dois momentos precisos, ou melhor, em duas direções da sua atividade intelectual, Espinoza é como que forçado a dar atenção aos problemas da linguagem: uma diz respeito à sua necessidade de construir uma exegese racional das Sagradas Escrituras; outra surge das questões colocadas no quadro da sua teoria do conhecimento" (POMBO, 2011, p. 16). 
qualquer semelhança. Por exemplo, um romano passará imediatamente do pensamento da palavra pomum [maçã] para o pensamento de uma fruta, a qual não tem qualquer semelhança com o som articulado, nem qualquer coisa de comum com ele a não ser que o corpo desse homem foi, muitas vezes, afetado por essas duas coisas, isto é, esse homem ouviu, muitas vezes, a palavra pomum, ao mesmo tempo que via essa fruta (SPINOZA, 2010, p. 113).

A questão da palavra pomum, para Spinoza, se origina com a experiência errática, do ouvir dizer (ex auditu) e do ler as palavras, e não passa de uma vox ou flatus vocis onde os homens atribuem convencionalmente. Segundo Chauí (1981, p. 33), “como numa flauta, diz Espinosa, as vogais são o som da música enquanto as letras são os orifícios tocados pelos dedos”. Isto por que em nós há uma concatenação de ideias fazendo com que associemos as palavras a outros pensamentos como pomum com a ideia de fruta e de maçã. Assim também, por exemplo, quando vemos as pegadas ou rastros de um cavalo, pensaremos logo num cavaleiro; um agricultor uma fazenda, etc. Para Spinoza, o homem tem seus afetos (que podem ser uma ação ou uma paixão) definidos como as afecções do corpo. Somos afetados por causas exteriores e temos ideias, muitas vezes, inadequadas, ou seja, confusas e mutiladas onde concebemos os signos, as palavras e as imagens. Assim, “[...] chamaremos de imagens das coisas as afecções do corpo humano, cujas ideias nos representam os corpos exteriores como estando presentes, embora elas não restituam as figuras das coisas" (SPINOZA, 2010, p. 111). Por conseguinte, há uma distinção entre a Ideia e a Imagem, pois, “[...] por ideias, compreendo não as imagens como as que se formam no fundo do olho, ou se preferirem, no cérebro, mas os conceitos do pensamento" (SPINOZA, 2010, p. 147). 
O filósofo holandês, em geral, parece criticar o conhecimento de primeiro gênero, a saber, da imaginação, da opinião, do ouvir dizer e do ler as palavras. Desta forma, podemos ver que a linguagem, para Spinoza, bem está enquadrada como um simples modo de imaginar do homem que é afetado por imagens, signos, palavras, etc. Há também uma relação com as noções comuns ou universais ditas anteriormente $^{13}$. O filósofo atribui o erro do conhecimento às imagens que temos das coisas: "Não é, pois, surpreendente que, dentre os filósofos que pretenderam explicar as coisas naturais exclusivamente pelas imagens dessas coisas, tenham surgido tantas controvérsias" (SPINOZA, 2010, p. 133). Há também um evidente apontamento para o problema dos nomes às coisas:

[...] a maior parte dos erros consiste em não aplicarmos corretamente os nomes às coisas. Pois quando se diz que as retas que vão do centro do círculo à sua circunferência não são iguais é, certamente, por que se está compreendendo do círculo, ao menos nesse momento, algo diferente daquilo compreendido pelos matemáticos. Igualmente, quando os homens erram ao fazer um cálculo, é por que tem na mente números que não são os que estão no papel. [...] não acharíamos que eles erram, exatamente como não julguei que estivesse errado alguém que ouvi, recentemente, gritar que o seu pátio tinha levantado vôo em direção à galinha do vizinho,

13 "Foi, enfim, de causas semelhantes que se originaram as noções ditas universais como homem, cavalo, cão, etc. Ou seja, por se formarem, simultaneamente, no corpo humano, ao mesmo tempo, tantas imagens, por exemplo, de homens, que elas superam a capacidade de imaginar, não inteiramente, é verdade, mas o suficiente, entretanto, para que a mente não possa imaginar as pequenas diferenças entre as coisas singulares" (SPINOZA, 2010, p. 133). 
pois sua mente me parecia suficientemente clara (SPINOZA, 2010, p. 145, grifos nossos).

Na Parte II, capítulo XVI (Do uno, do verdadeiro e do Bom) dos Pensamentos Metafísicos (Cogitata Metaphysica), apêndice (1663) da primeira e única obra publicada em vida e assinada, os Princípios da Filosofia Cartesiana (Principia philosophiae cartesianae), Spinoza criticou a utilização de certos vocábulos como verdadeiro e falso, a princípio, pelo vulgo ${ }^{14}$ que julga as coisas mais pelos nomes do que pelas coisas ${ }^{15}$. Além disso, nesta obra, Spinoza utiliza o cartesianismo para refutar os filósofos medievais, por exemplo, no que se refere à diferença entre o ente real e o ente de razão (os chamados transcendentais) ou como simples modos de imaginar, assim como os nomes. Por sua vez, na Ética, temos outra distinção que envolve o conceito de ideia, que para Spinoza, é verdadeira e adequada, ou seja, quando ela concorda com o seu ideado; assim, distingue a ideia e as palavras: "É preciso também fazer uma cuidadosa distinção entre as ideias e as palavras pelas quais significamos as coisas" (SPINOZA, 2010, p. 149). A ideia (modo de pensar/conceito da mente) envolve tanto uma afirmação como uma negação (ibidem), portanto, ela não está contida em imagens ou palavras uma vez que, a essência das

${ }^{14}$ Segundo Spinoza (2015, p. 215), "o vulgo primeiramente encontra os vocábulos, que depois passam a ser usado pelos filósofos, por isso compete àquele que procura a primeira significação de um vocábulo inquerir o que ele primeiro denotou para o vulgo; principalmente na falta de outras causas que, para investigá-la, pudessem ser retiradas da natureza da língua"

15 "A dissociação entre aquilo que é nomeado, o próprio nome e a ideia do que é nomeado, ou, em outros termos, o realismo semântico que estabelece a cisão entre coisa, palavra e pensamento não aparece na tradição filosófica com Spinoza, mas remonta às próprias origens do pensamento metafísico ocidental" (LEITÃO, 2010, p. 31). 
palavras e das imagens pertence aos movimentos corporais (extensão) e a essência da ideia pertence ao conceito do pensamento, a exemplo da mente:

[...] como as palavras são partes da imaginação, isto é, fingimos muitos conceitos na medida em que, vagamente, por alguma disposição do corpo, são compostos na memória, não se deve duvidar de que também as palavras, como a imaginação, podem ser a causa de muitos e grandes erros, se com elas não tivermos muita precaução (SPINOZA, 1983, p. 63).

Ao analisarmos estes exemplos, a partir da Parte II da Ética, podemos dizer, segundo alguns pesquisadores spinozanos, como Chauí (1981), que a linguagem na filosofia de Spinoza, seja como signo, imagem, nome ou palavra, atrapalharia para a via segura do pensamento seja claro e distinto, ou das causas e efeitos necessários das coisas (o conhecimento intuitivo que é imediato). Assim, a linguagem estaria ao lado do erro e exterior ao intelecto pela busca do verdadeiro, pois, através do corpo, a linguagem é uma atividade imaginativa sujeita a todos os enganos e mal-entendidos pela imaginação. Esta é a razão pela qual Spinoza teria feito uma dicotomia entre o pensamento (a ideia) e o imaginativo (primeiro gênero de conhecimento) A ideia sendo verdadeira, ou seja, adequada, proporcionaria a certeza das coisas, ao contrário, aquilo que é fruto das afecções do corpo, dos afetos e das paixões por causas exteriores (nossas percepções) nos proporcionariam a falsidade das coisas.

\section{A hermenêutica bíblica e o método histórico-crítico}

Em 1656, Spinoza por questionar os preceitos da Sinagoga judaica é excomungado aos 23 anos, acusado de heresia por 
materialismo e desprezo ao Torá. É excomungado com uma espécie de maldição (o Herem) que lhe baniria totalmente de toda a comunidade judia (a qual esteve inserido desde a infância já que tivera uma família judia portuguesa) ${ }^{16}$ e do contato social em geral. Marilena Chauí (1995, p. 8) problematiza este fato com precisão:

Afinal, o que dissera o jovem Baruch Espinosa, em 1656, o que dissera o filósofo, em 1670, e o que deixara escrito, em 1678, para que fosse expulso da comunidade judaica e condenado pelas autoridades cristãs? Que se passa no século XVII para que seu pensamento seja considerado como veneno, blasfêmia e abominação?

Segundo Deleuze (2002, p. 11), Spinoza "recusava penitenciarse e buscava, ele próprio, a ruptura. [...] em vez de se retratar, Espinosa redigiu uma Apologia para Justificar a sua saída da Sinagoga, ou, ao menos um esboço do futuro Tratado TeológicoPolítico". Desde os seus vinte anos, Baruch Spinoza começou a "expressar sérias dúvidas sobre o tradicional conceito de Deus, a vida após a morte e a veracidade da Bíblia" (HUENEMANN, 2012, p. 92). Conforme assinalou Nogueira (1976), desde cedo, Spinoza teve acesso aos estudos de hebraico. Na escola judaica Árvore da Vida (Etz HáHaim) dirigida por Menasseh ben Israel, Spinoza aprendeu as primeiras letras, o hebraico, além dos textos do Antigo Testamento, sobretudo sua tradução para o português e espanhol. Além disso, teve acesso às várias interpretações da Bíblia como o Livro dos

${ }^{16}$ Cf. ROVIGHI, 1999, p. 176: "O pensamento de Spinoza se formou sob a influência da Bíblia, especialmente o Antigo Testamento, e do Talmude; da Escolástica judaica medieval (especialmente Maimônides e Avicebrón); do pensamento renascentista, da nova ciência, e da escolástica do século XVI e XVII."

Diaphonía, ISSN 2446-7413, v. 2, n. I, 2016 
Profetas. Em outra escola, a Coroa da Torá (Keter Torá), dirigida por Saul Levi Morteira, os estudos do filósofo holandês se expandiram para a exegese dos textos sagrados. Depois da excomunhão, o filósofo holandês passou a assinar em suas cartas o nome de Benedictus de Spinoza com a sigla B. D. S. Por este motivo que, atualmente, os estudiosos de Spinoza tomam o seu nome latinizado como o mais coerente para referi-lo. O nome, porém, tem variado, evidentemente, segundo vários tradutores, pois escrevem também Spinoza, Spinosa, Espinosa e Espinoza. Sua filosofia, considerada de cunho "racionalista absoluto"17, apresentou-se, sem dúvida, como "divisor de águas entre a liberdade (de pensamento, de expressão e de ação) e de servidão (ética, política e teológica). Nisso reside seu enorme perigo para as ideias vigentes e os poderes estabelecidos" (CHAUI, 1995, p. 10). Seguindo apenas a luz natural (lumen naturale), Spinoza tentou livrar-se de qualquer superstição na filosofia e na religião.

Publicado, anonimamente, em Amsterdã, com a falsa indicação "Hamburgi, apud Kühnrath" (apesar de que logo descobriram sua autoria), o Tratado Teológico-Político (1670) tratou acerca da religião e do Estado, mais precisamente, a questão da separação entre Estado e Igreja, política e religião, filosofia e revelação. Segundo Spinoza, a Bíblia foi escrita para um povo inteiro, ou melhor, para uma nação específica. Seu conteúdo foi adaptado à compreensão das massas, e, em certo sentido, ao senso comum. No Teológico-Político, o filosofo holandês faz uma análise interpretativa do Antigo Testamento da

\footnotetext{
17 Para um estudo crítico acerca do racionalismo de Spinoza cf. NOGUEIRA, 1976, p. 43-44: "[...] a razão que utilizou, não se esgotou em si mesma, porque não era estática, à semelhança da de quase todos os racionalistas comuns. Por isso, ele [Spinoza] foi, como pretende a grande maioria, apenas racionalista, ou muito menos, como ainda querem outros - racionalista puro."
} 
Bíblia, no Capitulo VII, e tira várias conclusões polêmicas a respeito de seu conhecimento (como veremos adiante). A tarefa da interpretação é refazer a história do texto bíblico por meio da história da língua hebraica e saber sobre aqueles que escreveram as Escrituras e para quem as destinaram.

No Capítulo I, Spinoza tratou acerca das profecias. A profecia consistia, segundo o filósofo, numa revelação ou um conhecimento natural certo de algo revelado por Deus. Spinoza admitia que, em suas funções, os profetas judeus sofriam com as incertezas proféticas em relação à imagem e ao espírito de Deus.

[...] Tudo aquilo que ia além da capacidade de compreensão dos judeus e tudo aquilo de que, na altura, ignoravam as causas naturais era habitualmente atribuídas a Deus. A tempestade chamavam de repreensão de Deus, aos trovões e relâmpagos flechas de Deus (SPINOZA, 2003, p. 25).

O problema consistia no fato de que os profetas eram confusos, logo, pois, utilizaram de uma linguagem parabólica e enigmática para escrever a Bíblia. Os autores das Sagradas Escrituras utilizaram, muitas vezes, da imaginação para explicar algumas coisas que nem eles mesmos entendiam, a exemplo da revelação divina. É importante salientar o que dizia Spinoza acerca das leis. As leis que, de fato, podiam ser classificadas em humanas e divinas. No capítulo IV, Spinoza tratara a lei divina como universal ante a natureza e que representava a verdadeira ética humana. O filósofo a designa como soberano bem e como o verdadeiro conhecimento e amor a um Deus imanente (a substância como vimos). Spinoza, neste sentido, explicita as leis formadas por homens contraditórios que acreditaram num Deus antropomórfico castigador e julgador. Outro grande 
problema que envolvia o trabalho de um profeta seria a questão da narração dos milagres. É o que Spinoza menciona no Capítulo VI (Dos Milagres). Os milagres são aquilo que o vulgo acredita serem obras de Deus ou fatos insólitos da natureza que compreendem por devoção e por admiração: "E, de fato, isso agrada de tal maneira os homens que, até hoje, ainda não pararam de inventar milagres para fazer crer que Deus os ama a eles mais do que aos outros" (SPINOZA, 2003, p. 96).

Portanto, para Spinoza, seria um absurdo considerar os milagres como verdades reveladas uma vez que seriam fatores corruptíveis com as leis da natureza. Mais adiante, no capítulo XII, o filósofo argumentara se a Bíblia foi, realmente, considerada a palavra de Deus. Spinoza (2003, p.114) combateu a ideia da Escritura como a palavra de Deus nestes termos: "É ver como andam quase todos fazendo passar por palavra de Deus as suas próprias invenções e não procuram outra coisa que não seja, a pretexto da religião, coagir os outros para que pensem o mesmo". Neste sentido, a Bíblia, diferentemente de um conhecimento natural e racional, não passaria de um conhecimento transmitido por meio de imagens, ou seja, de um modo de imaginar (como vimos acima) oriundo do primeiro gênero de conhecimento (imaginativo ou opinativo). Assim, não encontramos nela nenhuma verdade filosófica ou científica. Segundo o filósofo holandês, a Escritura é dita sagrada para induzir aos homens a devoção para com Deus e em seus estudos do sentido da Palavra de Deus, concluiu que ensinaram: 1) a verdadeira religião, 2) profecias futuras e 3) Luz sobrenatural aos autores. Eis a crítica que Spinoza (2003, p. 197) faz aos profetas: "E, de fato, é que, de tão santos pretenderem ser, eles convertem a religião em superstição e comecem até adorar simulacros e imagens, isto é, de papel e tinta, 
como se fossem a palavra de Deus".

Diante do problema teológico com suas intolerâncias e fanatismos (sobretudo em um Estado teocrático), Spinoza pretendeu explicar o sentido de um verdadeiro Estado, pois, foi a favor de um Estado democrático, considerado o mais natural dos regimes onde todos os homens pudessem ser livres para pensar o que quiser e dizer aquilo que pensa. É o que trata no último capítulo do Tratado Teológico-Político. O homem é dotado de um discernimento apesar da pressão de um determinado poder de Estado com supremos direitos (determinado pela sua potência). O homem tem todo o direito de se expressar tanto filosófico como religiosamente e de agir desde que não prejudique radicalmente a legislação estabelecida. $\mathrm{O}$ Estado democrático seria, portanto, aquele que teria como fim a liberdade segundo o direito natural do homem, sobretudo libertando-o do medo e da repressão.

Sob o viés do Tratado Teológico-Político, Spinoza passou a ser considerado o precursor da moderna exegese ${ }^{18}$ do século XVII a partir da realização de uma hermenêutica bíblica. Segundo Rovighi (1999, p.204):

${ }_{18}$ Para um estudo preciso sobre a interpretação da Escritura em Spinoza, cf. o clássico ZAC, 1965, p. 1-2: "Les sciences bibliques, telles qu'on les conçoit et les pratique de nos jours, sont des sciences historiques. Nous verrons que c'est ainsi que Spinoza lui-même les conçoit: l'interprétation de L'Écriture doit être détermininée par l'histoire de as rédaction seule. D’òu cette affirmation d'Aldolphe Lods que Spinoza est l'initiateur de la critique biblique." "As ciências bíblicas, de tal forma que a gente concebe e as pratica em nossos dias, são ciências históricas. Nós veremos que é assim que Spinoza ele mesmo as concebe: a interpretação da Escritura deve ser determinada pela história de sua redação somente. Donde esta afirmação de Aldolphe Lods que Spinoza é o iniciador da crítica bíblica" (Tradução livre). 
[...] Spinoza dá algumas regras de exegese que se resumem nesta: o método para interpretar a Bíblia não deve diferir daquele de interpretar a natureza; para uma como para outra, deve-se começar da história, isto é, do compêndio dos fatos: fatos naturais para a natureza, documentos e textos para a Escritura.

Spinoza analisa a Bíblia quanto a sua escrita originária e a história dos que a escreveram vendo até que ponto ela pretendia instaurar a ordem moral e civil sob a ordem natural do homem. Para tanto, é a partir do método histórico-crítico que ele faz um combate ao irracionalismo e à superstição nos escritos proféticos. No Tratado Teológico-Político, precisamente no capítulo VII, Spinoza trata Da interpretação da Escritura no sentido em que avalia o seu conhecimento em si (a linguagem originariamente empregada) e não da questão, muitas vezes, da fé em seus escritos (metafóricos). Tratase de uma interpretação da Escritura pela Escritura, pois, não é um livro com sentido transparente e apreensível como um texto filosófico, científico ou geométrico. Assim, segundo Spinoza (2003, p. 117), "todo o conhecimento sobre a Escritura deve, portanto, extrair-se unicamente dela mesma”. Neste sentido, a questão da interpretação bíblica em Spinoza parece como saber histórico e conforme Abbagnano (2014, p. 666):

O Racionalismo seiscentista se inserirá nessas premissas, reservando o trabalho interpretativo aos textos e trechos da Escritura que, obviamente, não admitem compreensão literal: é esse o princípio que se encontra exposto no Tratactus theologicus-politicus (Cap. VII) de Espinosa.

O filósofo holandês buscou, com o chamado método históricocrítico, as condições pelas quais a Bíblia pudesse ser acessível ao 
entendimento humano, ou seja, a necessidade de uma interpretação que estivesse no nível de um conhecimento claro e distinto (racional). O método exegético de Spinoza diferiu dos empregados pelos talmudistas e pelos comentadores judeus. Segundo Nogueira (1976, p. 78), o pensador holandês não foi motivado pelos comentadores hebreus que teve acesso como Fílon de Alexandria, Gabirol, Maimônides, Gersonides, Creskas, Léon Hebreu entre outros. O Rabino Jehouda Alphakar de Barcelone teria sido, segundo Nogueira (1976, p.85), o que defendeu a independência da filosofia spinozana em relação ao judaísmo, um dos possíveis influenciadores judeus de Spinoza. Para Alphakar, a razão devia submeter-se à Escritura e em determinadas passagens, era necessário interpretar a Bíblia no sentido literal mesmo que repugnasse a razão. Em relação, entretanto, a Maimônides, há uma grande diferença de seu método interpretativo do utilizado por Spinoza, pois, para este, o conhecimento da Escritura deve ser obtido nela mesma, mas para àquele, o conhecimento da Escritura deve estar de acordo, necessariamente, com a razão. Segundo Zac, Spinoza não quis refutar outros intérpretes bíblicos, com exceção dos princípios de interpretação feitos por Maimônides, pois, este "afirma, ao contrário, que não pode haver contradição entre as verdades reveladas e as verdades filosóficas, entre a fé e o saber" (ZAC, 1965, p. 16). Além disso, para Zac (1965), outra diferença entre os métodos interpretativos de Maimônides e de Spinoza consiste em que, neste, a interpretação é literal (explica a Escritura pela Escritura como vimos) enquanto que, para aquele, o método é alegórico e místico (conforme escreveram os profetas).

Somente através da análise filosófica a que Spinoza chama de "luz natural" é que percebemos a linguagem alegórica e metafórica 
dos profetas. Segundo Durant (1999, p. 166), a linguagem metafórica da Bíblia expressava tendências orientais segundo a qual os profetas transmitiam sua doutrina pela imaginação e adaptavam essa capacidade à mente popular. Por conseguinte, Spinoza (2003, p. 115116) compara seu método de interpretar a Escritura ao método de interpretar a Natureza:

[...] o método de interpretar a Escritura não difere em nada do método de interpretar a natureza; concorda até inteiramente com ele. Na realidade, assim como o método para interpretar a natureza consiste essencialmente em descrever a história da mesma natureza e concluir daí, com base em dados certos, as definições das coisas naturais, também para interpretar a Escritura é necessário elaborar a sua história autêntica e, depois, com base me dados e princípios certos, deduzir daí como a legítima consequência o pensamento de seus autores.

O método histórico-crítico teve diversas preocupações tais como, em estudar o contexto histórico dos autores da Bíblia, a época que viveram e seus costumes sociais e políticos. ${ }^{19}$ Mas, Spinoza admitiu, em seu Tratado, algumas dificuldades do método tais como o difícil acesso à língua hebraica cujo tempo devorou os textos antigos. "Mas que tipo de dificuldade apresenta esse método? O que é que lhe falta para que nos possa levar até o conhecimento total e seguro dos Sagrados Códices?" (SPINOZA, 2003, p. 124). Diante desta dificuldade, o pensador holandês viu a necessidade de conhecer a

\footnotetext{
19 "[...] a história da escritura deve descrever os pormenores de todos os livros dos profetas de que chegou notícia até nós, ou seja, a vida, os costumes, os estudos de cada um dos autores, quem era ele, em que ocasião, em que época, para quem e, finalmente, em que língua escrevia" (SPINOZA, 2003, p. 119).
} 
história da língua hebraica ${ }^{20}$. Assim, dedicou-se aos estudos da língua escrevendo um inacabado Compêndio de Gramática da Língua Hebraica (1677) publicado postumamente. ${ }^{21} \mathrm{O}$ Compêndio foi escrito com uma única parte com 33 capítulos sobre a etimologia e flexão dos nomes e dos verbos. Numa advertência ao leitor, de Jarig Jelles (amigo de Spinoza), no prefácio da edição das obras póstumas (Opera Posthuma, 1677), temos:

A composição deste Compêndio de Gramática da Língua Hebraica que aqui te é oferecida, benévolo leitor, foi empreendida por seu autor a pedido de alguns amigos seus mui desejosos de estudar a língua sagrada. Dela imbuído desde a sua infância, e tendo-se dedicado posteriormente a estudar suas obras com afã, possuía esse gênio que permite compreendê-la, sendo extremamente versado nela e conhecendo-a à perfeição. E isso hão de sabê-lo todos os que se consagram a ela e não se desdenhem ler estes poucos escritos que, como muitos outros, a morte inesperada do autor deixou inacabados. Seja como for, benévolo leitor, queremos tornar-te partícipe dela e não duvidamos de modo algum que a obra do autor e o nosso esforço para prestar-te serviço ter serão gratos (SPINOZA, 2014, p. 397).

Segundo Spinoza (2014, p.427), no capítulo VII (Do gênero

${ }^{20}$ Segundo Spinoza (2003, p. 117), “[...] e uma vez que todos os autores, tanto os do Antigo como os do Novo Testamento, foram Hebreus, é evidente que a história da língua hebraica é necessária para se compreenderem”.

${ }^{21}$ Para uma tradução mais recente desta obra Cf. SPINOZA, 2014. Para um estudo aprofundado sobre o Compêndio e sua relação com o método geométrico (more geométrico) spinozano, cf. SANTIAGO, 2014, p. 9: "A leitura da obra nos lança em muitas questões: que entende Espinosa por gramática? Trata-se de um tratado da filosofia da linguagem? Ou trata-se de um tratado de filosofia sobre a particularidade de uma língua? Em que sentido esta gramática é uma dedução geométrica?". 
masculino e feminino) do Compêndio, muitos foram os que escreveram uma gramática das Sagradas escrituras, mas nenhum que tenha feito uma gramática da língua hebraica. Além disso, Spinoza (2003, p. 125) alegou, no capítulo VII do Tratado Teológico-Político, a carência de dicionário, gramática ou retórica sobre o hebraico. $\mathrm{O}$ objetivo do filósofo holandês foi de mostrar que a língua hebraica não é a única verdadeira para revelar o Ser ou as coisas divinas, mas uma língua usual de um determinado contexto histórico. E como uma língua particular, tem seus vícios, obscuridades e ambiguidades. Spinoza apresentou, assim como, no Tratado Teológico-Político, a história do uso de uma língua utilizada pelos falantes hebreus. $\mathrm{O}$ conhecimento das verdadeiras autorias das Escrituras, com seus livros apócrifos e o modo como os variados livros reuniram-se num só corpo, por exemplo, foram também outras dificuldades do método histórico-crítico, visto que, os autores do Novo Testamento apenas leram e tentaram "hebraizar" o Antigo Testamento. Este "hebraizar" foi uma tentativa de leitura e interpretação dos autores, sobretudo João que "hebraiza" em grego, do Novo Testamento, que não tiveram aquele conhecimento originário da língua hebraica do Antigo Testamento. Segundo Homero Santiago (2014, p.6o-61), sobre a afirmação spinozana de que João havia hebraizado em grego, “[...] vários aspectos das frases hebraicas diferem dos 'modos de falar' (loquendi modi) das línguas europeias, e João fazia frases em grego exprimir modos de falar típicos do hebraico, o que evidentemente gera confusões interpretativas”

Além disso, a linguagem oral dos judeus, sobretudo com a diáspora, permitiu que a escritura fosse difundida com elementos de outras culturas impossibilitando, segundo Spinoza, uma compreensão original do Antigo Testamento. O filósofo holandês, no 
capítulo VII do Teológico-Político, constatou que a linguagem empregada na Escritura, estava cheia de erros, de contradições, de ambiguidades e de obscuridades nas frases por conta da complexa fonética hebraica. Os leitores vulgos, no entanto, tinham a Bíblia como um livro único, pois, eram ignorantes de sua verdadeira origem e não sabiam em que sentido empregava cada texto. Nas Escrituras encontraríamos algo não muito contrário à razão, mas preceitos morais e políticos que tinham a finalidade de manipular o povo ordenhado pela Comunidade Judaica até então considerada eleita e privilegiada por Deus. Por esse motivo, explica histórico e filologicamente a questão das autoridades na interpretação da Bíblia como uma lei dando exemplo dos Pontífices romanos. Segundo Spinoza (2003, p. 138), "se, de fato, cada um possui plena autoridade para interpretar a Escritura, então, a norma para essa interpretação só pode ser a luz natural comum a todos e não uma luz qualquer superior a natureza". Para Spinoza cada um deve e pode, conforme a condução da luz natural, interpretar a Escritura pelo método exposto e não apenas uma autoridade externa qualquer, pois, o

[...] método não deve ser tão difícil que só os filósofos muitos argutos o possam seguir; deve é ser um método que em consonância com a índole e a capacidade natural comum dos homens, conforme demonstramos ser o caso do nosso (SPINOZA, 2003, p. 138).

Uma vez exposto o método de interpretação, Spinoza direciona-se àqueles (teólogos) que, defendendo o discurso sobrenatural da Bíblia, o criticam por utilizar o método pela luz natural:

Resta-nos agora examinar as opiniões daqueles que discordam 
de nós. Em primeiro lugar, a dos que sustentam que a luz natural não tem capacidade para interpretar a Escritura e que, para o fazer, é absolutamente necessário a luz sobrenatural (ibidem).

Para Spinoza, é inconcebível o que os profetas pretendiam já que pareciam alimentar suas próprias dúvidas, pois, suas explicações nos textos bíblicos mais pareciam conjecturas do que sobrenaturais. Neste sentido, a dificuldade da interpretação da Escritura não consiste na insuficiência da luz natural (razão), mas na preguiça ou malícia dos homens que negligenciaram a história da escritura. Por conseguinte, o filósofo holandês salientou o papel dos profetas como políticos e que tinham a finalidade, de certa forma, de impor a palavra divinizada na Escritura como uma lei moral sob a sociedade. Para tanto, percebeu o que tinha relacionado à transição do Antigo para o Novo Testamento, segundo o qual no Antigo testamento havia uma lei mosaica, exemplo da "pena de talião" (olho por olho, dente por dente), marcado por um Estado autoritário e poderoso. Além disso, trata-se de uma época em que a escravidão e os sacrifícios eram comuns. E no Novo Testamento onde o Estado apresentava-se enfraquecido e constituído de cidadãos oprimidos segundo uma lei cristã embasada pela ideia da culpa, da resignação e da humildade. $\mathrm{O}$ texto spinozano deixou explícita uma crítica em relação à preservação do Estado judaico com a autoridade teológico-política que impõe, com atributos e leis humanas, a lei divina como moral imposta.

Spinoza, neste sentido, foi visto por muitos como um reformador radical de toda uma manipulação intelectual envolvendo a religião sob vários pontos, tanto no meio social como político. Por outro lado, fora mal visto pela sociedade, sobretudo da comunidade 
judaica holandesa, que se fundamenta na religião fanática e supersticiosa nos seus ensinamentos bíblicos. As paixões fracas tais como o medo, retrata Spinoza, é algo que contribui para a superstição. O medo e a preocupação com a vida e a morte, a culpa diante da divindade e a esperança de uma salvação transcendental exemplificam a superstição religiosa. As pessoas acreditam, muitas vezes, pela imaginação, na ruptura com as leis naturais vigentes quando pensam em milagres. A partir da imaginação podemos inferir diversas ideias e inspirações de caráter simbólico e místico (para Spinoza, a linguagem, as imagens e os demais signos). A Bíblia é um exemplo dado por Spinoza de toda uma moral imposta, através do poder das palavras e de sua persuasão composta de superstição, logo, de fantasias e coisas ligadas ao sobrenatural. Contra isso, Spinoza vai além e admite que o papel político de cada profeta e teólogo seja o controle moral e religioso sobre o senso comum, pois, não convêm com a razão certas coisas admitidas pelos autores da Bíblia que "serviram-se de histórias miraculosas pela mesma razão que usavam parábolas, [que] era uma adaptação necessária à mente do público" (DURANT, 1999, p. 167).

Mais ainda, Spinoza percebeu o uso fraudulento da Bíblia pelo Estado (teocrático) a ponto de perceber que o poder soberano quer manter o povo sob a superstição. Para tanto, é dessa forma que Spinoza percebe a superstição na religião, com tirania e domínio sobre as massas ignorantes. $\mathrm{O}$ irracionalismo religioso é marcado pela falta de conhecimento das verdadeiras causas e de ideias verdadeiras da natureza que Spinoza a chama, como vimos acima, de substância absolutamente infinita ou Deus. Por conseguinte, a solução dada pelo filósofo holandês contra esta superstição e servidão seria a ética do conhecimento que tem o homem como um 
ser livre e pensante cuja potência age em prol de afetos ou paixões alegres e ideias adequadas.

\section{Considerações finais}

A filosofia proposta de Spinoza, nas suas várias obras aqui mencionadas, tinha um caráter ontológico e epistemológico, sobretudo, marcado pela ordem geométrica e, desta forma, não nos apresentou tratados sistemáticos acerca da linguagem. No texto da Parte II da Ética, no Breve Tratado, na Correção do Intelecto, entre outras, encontramos exemplos práticos (mas escassos em termos contemporâneos tratados pela filosofia analítica) que envolvem a questão dos nomes, das palavras e das imagens que são postas, muitas vezes, como erros do intelecto percebidos por causas exteriores, como os afetos ou afecções do corpo, por exemplo. Além disso, o entendimento dos conceitos como o de Imaginação e de memória que são importantes para entendermos a teoria da ideia verdadeira, apresentada por Spinoza como seu próprio método racionalista. E desta forma, a conclusão de que, em Spinoza, a linguagem pode ser vista como signos tais como os nomes, as palavras ou o modo de imaginar do homem que pertence a um conhecimento mais inferior. Mesmo que Spinoza tenha contraposto o modo de pensar (a ideia adequada ou verdadeira) e o modo de imaginar (a ideia inadequada e a imaginação) ${ }^{22}$, percebemos que a linguagem, neste contexto, mesmo que não ofereça ao intelecto um conhecimento tão claro e distinto, é indispensável e é o princípio de

22 Segundo Chauí (1981, p. 41), existe dois modos de pensar, o primeiro, são as ideias que concebem a existência das coisas fora dos espíritos; o segundo são as imagens enquanto afecções de nosso corpo na relação com os outros. 
todo o conhecimento. A prova disso é que a linguagem é, para Spinoza, o primeiro gênero do conhecimento humano, pois, seria uma contradição por parte do próprio filósofo desconsiderar a linguagem numa exposição ética geométrica onde é fundamental certa utilização de conceitos e de definições. Esta posição é tomada semelhantemente por Olga Pombo (2011, p. 28):

Sabemos que Espinoza usa, de forma intencional e explícita, uma metodologia dedutiva para o estabelecimento do seu sistema, no qual, a partir de princípios primeiros autoevidentes (hipotéticos) e com a ajuda de definições, scholium e corolários, deduz a natureza da humanidade. A questão é a seguinte: como explicar que Espinoza, sem ter dado uma especial atenção aos temas linguagem, tenha deixado um monumento tão perfeito como a Ethica, onde tenta aplicar o estilo que ele mesmo elegera?

Por conseguinte, há em Spinoza, num primeiro momento, um convencionalismo acerca da linguagem, uma vez que ele considera a linguagem como atribuições estritas da natureza humana, dado a maneira como imaginamos e somos afetados, corporalmente, produzindo e percebendo as imagens, as palavras, os signos, etc. Esta abordagem spinozana da linguagem como uma convenção ao uso prático do homem em sua cultura e sociedade é o que mais tarde a filosofia analítica trabalhará com a chamada "pragmática". Se a linguagem se tornou "negativa" na filosofia spinozista é porque ela precisaria antes ser guiada pelo entendimento (racional e ligado às causas das coisas) e não pela imaginação (ligada aos efeitos das coisas).

Como vimos, todavia, com a hermenêutica bíblica demonstrada no Tratado Teológico-Político, podemos notar que 
Spinoza se preocupou com a importância da linguagem, principalmente, no que se refere à clareza e à racionalidade de seu discurso. Spinoza ao propor um método histórico-crítico das Sagradas Escrituras não apenas se preocupou em combater os dogmas da religião judaica em geral, mas a forma como a linguagem profética escrita despertou para o povo leigo os modos de imaginação e as ideias como as metáforas, as ambiguidades e as obscuridades. Neste sentido, a melhor forma de conhecer a linguagem bíblica, decifrá-la e torná-la adequada ao intelecto seria pela sua análise filológica (a originalidade da língua hebraica) e histórico-crítica (o contexto social e político judeu). Assim, podemos considerar Spinoza, além de crítico da linguagem, também um hermeneuta e gramático visto que, em seu Tratado Teológico-Política, dedica-se como um filólogo do hebraísmo bíblico e em seu Compêndio de Gramática da Língua Hebraica, como um gramático do hebraico.

\section{Referências bibliográficas}

ABBAGNANO, N. Dicionário de filosofia. Tradução de Ivone Castilho Benedetti. São Paulo: Martins Fontes, 2014.

CHAUI, M. Da realidade sem mistérios ao mistério do mundo:

Espinosa, Voltaire e Merleau-Ponty. São Paulo: Brasiliense, 1981.

. Espinosa: Uma Filosofia da Liberdade. São Paulo: Moderna, 1995. (Coleção Logos).

DELEUZE, G. Espinosa, filosofia prática. Tradução de Daniel Lins e Fabien Pascal Lins. São Paulo: Escuta, 2002.

DURANT, W. A história da filosofia. Tradução e notas: Luiz Carlos do Nascimento Silva. São Paulo: Nova Cultural, 1999. (Col. Os Pensadores). 
GLEIZER, M. A. Metafísica e conhecimento: ensaios sobre Descartes e Espinosa. Rio de Janeiro: EDUERJ, 2014.

HUENEMANN, C. Racionalismo. Tradução de Jaccques A. Wainberg. Petrópolis, RJ: Vozes, 2012.

LEITÃO, G. D. de A. Introdução ao problema da linguagem na filosofia de Spinoza. In: UFRJ, Linguagens e Diálogos, v.1, nº 1, p. 2441, 2010.

NOGUEIRA, A. O método racionalista-histórico em Spinoza. São Paulo: Mestre Jou, 1976.

POMBO, O. Espinoza e a linguagem. In: CID: Revista de Ciência da Informação e Documentação, Ribeirão Preto, v. 2, nº 1, p. 16-30, jan./jun. 2011. Disponível em:

<http://revistas.ffclrp.usp.br/incid/article/view/63/pdf>. Acesso em: 20 de Junho de 2015.

RAMOND. C. Vocabulário de Espinosa. Tradução: Claudio Beliner. São Paulo: Martins Fontes, 2010.

ROVIGHI, S. V. B. “Spinoza”. In: História da Filosofia Moderna. São Paulo: Loyola, 1999.

SANTIAGO, H. Geometria do instituído: estudo sobre a gramática hebraica espinosana. Prefácio de André Menezes Rocha. Fortaleza: EdUECE, 2014. (Coleção Argentum Nostrum).

SPINOZA, B. Breve Tratado. Tradução e Notas de Emanuel Angelo da Rocha Fragoso e Luis César Guimarães Oliva. Belo Horizonte: Autêntica, 2012. (Coleções Filô/Espinosa).

. Ética. Edição bilíngue Latim-Português. Tradução e Notas de Tomaz Tadeu. Belo Horizonte: Autêntica, 2010.

. Obra Completa IV: Ética e Compêndio de Gramática da Língua Hebraica. Tradução de J. Guinsburg, Newton Cunha e Roberto Romano. São Paulo: Perspectiva, 2014. 
. Princípios da Filosofia Cartesiana e Pensamentos

Metafísicos. Tradução de Homero Santiago e Luís César Guimarães Oliva. Belo Horizonte: Autêntica, 2015. (Coleções Filô/Espinosa).

. Tratado da Correção do Intelecto. In: Espinosa. Tradução e notas: Carlos Lopez de Mattos. São Paulo: Abril, 1983. (Coleção Os Pensadores).

. Tratado Teológico-Político. Tradução e notas: Diogo Pires Aurélio. São Paulo: Martins Fontes, 2003.

TEIXEIRA, L. A doutrina dos modos de percepção e o conceito de abstração na filosofia de Espinosa. São Paulo: Editora UNESP, 2001. ZAC, S. Spinoza et l'interprétation de l'écriture. Paris: PUF, 1965.

Submissão: 28.04.2016 / Aceite: 20.05.2016 